\title{
The Effect of the Use Leadership Style Transformation and Non- use of Laissez-Faire in Schools on the Percentage of Outstanding Students and on the Percentage of Dropouts in Schools in the Haifa District
}

\author{
Kawther Younes ${ }^{1}$, Yousef Daher ${ }^{2}$ \\ Ph.D. Students Management Faculty, West University of Timisoara, Romani ${ }^{1,2}$ \\ E-mail: kawther_younes@hotmail.com
}

\begin{abstract}
This study attempts to discuss the effect of the use leadership style Transformation and Non-use of laissez-faire in schools on the percentage of outstanding students and on the percentage of dropouts in schools in the Haifa district. To achieve a goal of this study, a study was published on "Measurement and analysis of statistics to determine relationships between one data set and another". The leadership style used by teachers and principals. As an independent variable was identified from the literature, and appropriate statistical tests were performed to determine its effect.
\end{abstract}

Furthermore, the study lies that the school principal adopts a specific style of transformative, transformational leadership styles, if this leadership style influences the school culture. The sample of this study consists of the principals and teachers of the Arab outstanding students in the Haifa district. The test will include 4 Arab high schools in the Haifa district, 4 schools received a "good" rating.

Keywords: Leadership Styles, Transformational leadership styles, Transactional leadership styles, Lassiez-Faire styles, School culture. 


\section{Introduction}

Working this Engaged in patterns His role of the manager at home the book At home the book to opposite the impact of these on degree the motivation for learning And level Achievements of The students Classroom.

Opaltka (2015), with reference to his leadership of the manager at home the book, emphasizes you the importance of Patterns the leadership of Director, based On Values and features personality of the manager at home the book. The manager as a leader Educational there is to him role central in policy Management of Home The .book, in determining Procedures and methods working

Patterns the relationship between Director Home the book for teachers same as also editorial board the relationship between the manager and His Students Focus You Their interest of Researchers the dealers in education This a Number Decades. During Years The occupation Was In areas Following: Nature of editorial board The relationship between Director To the team the teachers And between the manager To his students, how this Is underway Went in fact Inside the class And between mural Home The book, expectations mutuality of the manager And the student, ways To impart discipline For students And management Class, teaching And learning As intermediaries Social, perception efficiency Self of The manager, emotions And beliefs The teacher And their impact On Belonging To school.

\section{Literature Review}

\section{Defining Leadership:}

The school, like other organizations, operates within a reality that dictates conditions of intensified competition, alongside increasing demands on the environment - students, parents, the Ministry of Education and more. This wide public of "stakeholders" does not always accept the professional authority of educators, yet challenges them. 
The prevailing expectation of educators is to demonstrate leadership, to present a vision that outlines an improved future picture of the educational-educational agenda, and to define practical processes through which the vision can be implemented and realized in practice. These challenges require educators to have leadership qualities that are not necessarily born with them, but it is substantial to raise awareness of them and nurture them within the school. There is an agreement in the literature with the perception and findings that two main variables influence the quality of students' learning in the school: the quality of the curriculum and teaching, and the quality of the pedagogical leadership of the school (Opeltech, 2015).

Leadership in education, in order to remain educational, must necessarily relate to diversity and be based on the cultivation of individuality. A leadership of personal power that does not navigate itself within the boundaries of the individual and the group may be an anti-educational leadership. One of the problems in educational leadership is the gap between the normative use of the term and the vagueness of the definition of behavior that is so expected. Clearly, the expectations of the achievements of educational leadership are unclear. The behavioral definitions themselves, due to the uniqueness of the educational leadership, have many dilemmas inherent in this phenomenon (Ben Asher, 2013).

\section{Transformational Leadership Style}

The transformational leadership theory is a cooperative, process-focused networking where the leader motivates his followers to create, inspire and influences changes in them. Leader of this style act as role model for his followers, attend their needs and involve them in the decision-action process. The main point in this theory is to encourage the followers to perform to their full capacity and meet the expectations. Transformational Leader requirement to have a base of transaction qualities to establish his style successfully. 
Transformational leadership is not a replace for transactional leadership, but rather its development and enhancement (Tomey, 2004).

Transformational and transactional leadership consists of seven dimensions (Bass, 1985; Avolio, Bass \& Jung, 1999) that developed a tool that encompasses all of those seven dimensions and is used to measurement the Ingredients of transformational leadership styles, leadership and non-interference. This gadget, called the Multifactor Leadership Questionnaire (Gumusluoglu, \& Ilsev, 2009)

Transformational leadership is abstemious in four dimensions: exemplary influence, thrilling motivation, intellectual energizing and personal consideration. In perfect effect, the leader does the "right thing", takes risks and sets an example for his followers, which makes him trusted and respected by his followers. Inspirational motivational leaders have high expectations and try to fill with and motivate their followers by changing their thoughts to fulfill the visions and expectations of their leader. Intellectual stimulation involves providing a supportive environment at work that encourages employees to be more creative, accept difficult tasks, and participate in the decision-making process. Finally, a leader who is considerate of others' feelings treats each employee as unique regarding their differences, and spends time coaching employees and values their accomplishments through continuous support. (Arnold, Turner, Parling, Kiloway, and Mackie, (2007).

A transformational leader is someone who motivates and inspires followers to achieve extraordinary results. --- Transformational leaders care about the interest and developmental needs of individual followers, they change the follower's awareness of issues by helping th em to look at old problems in a new way and are able to excite, excite and inspire followers to make an extra effort to achieve group goals (Odumeru \& Ifeanyi, 2013).

Transformational leaders strive to change those who lead them. By doing so, they can represent potential, self-replicating leadership. 
Not content with using the power of character(charismatic) or bargaining (transactional) to persuade followers, transformational leaders use knowledge, experience, and vision to transform those concerning them in a way that makes them deeply supportive followers that remain even when the leader who created them is no longer on the scene. Transformational leaders represent the most valuable form of leadership where followers are given an opportunity to change, transform, and in the process, develop themselves as stakeholders.

Organically speaking, this achieves the best leadership conclusion since transformational leaders developed individuals (Germano, 2010; Odumeru \& Ifeanyi, 2013; Northouse, 2016)

Transformational leaders prepare their followers for leadership. According to Jabbar, transformational leaders in Honarmand and Abdelsalam (2014) develop their followers to the point where the followers are able to assume leadership roles and perform beyond the set standards or goals. This means that transformational leaders try and achieve in raising colleagues, subordinates, followers, clients, or target groups to a higher level of awareness. This definitely leads to sustainable change, even after they leave leadership positions. Microsoft's Bill Gates is an example of a transformational leader. Microsoft started out as a managing owner, but today the company is run by professionals who also do research and development. It has also maintained Microsoft's leadership by managing and training any disruptive technologies to its advantage.

\section{Laissez-Faire Leadership Style}

Laissez-Faire leadership It can be described as a nondirective, passive and inactive style. Leaders of this style believe that internal drives and believes motivate the follower to act. The leader in this style sets some rules for handling problems in the organization and then delegates them to the subordinates. 
A leader needs to have a very good knowledge of the knowledge level, competence and integrity of his followers in order to be fit to delegate tasks. This flowering approach helps him utilize his talents and abilities to the fullest. It is more effective if used with a very mature and independent employee, but it is mostly not an effective or productive approach. (Daly, Speedy \& Jackson, 2004).

The risks here arise when the leader is mistaken in choosing the suitable employee to masterful the delegated tasks. The lack of a clear vision and way for the organization leads to followers adopting different goals and objectives, increasing the level of tension between followers and decreasing productivity and quality. Laissez-Faire leader do not influence the organization culture due to minimal interactions between him and his followers. Finally, Laissez-Faire leadership style fundamentally can be used in small business not for big organizations like health organizations (Daly, 2004).

Leaders use a variety of unlike oncoming. Some of them are authoritarian and prefer to tell their teams exactly what to do. Others use a more participatory approach. Still others might use a style somewhere in between these two extremes. ( Nicholson,2007)

Continuum describes running from high authority at one extreme (Tells) through the team having entire freedom to threat at the other. He could say "let it work" which is what defines other authors when leaders use condescension. Leaders ask the team to identify the problem, develop options, and make a decision. The Group is free to do what is needful to solve a problem while continuing to operate within reasonable limits, given organizational needs and goals. (Nicholson II,2007)

The laissez-faire method is referred to as "Those in Responsibility Avoid Decision Making" (Robins, 2007). Similar to the laissez-faire cases defined as "abdicating responsibilities and avoiding decision-making” (Luthans, 2005). Laissez-faire policy does not participate in the operation of the unit. 
This leadership style is difficult to defend unless the leader's subordinates are enthusiastic experts and specialists, such as scholars. "Leaders allow group members to make all decisions" (Mundy, 1995). The concept of "laissez-faire" is also given as "abdicating responsibilities and avoiding decisions". (Osborn, 2008).

Above all, the authors define leadership style "let it work" in their own words According to their definitions provided, the idea of this type of leadership is the same. The authors define the majority of these in the sense that in a laissez-faire leadership style, leaders usually do not want them to be involved in the decision-making operation of the subordinate process. The leaders allowed the subordinates to have the authority to make their personal decisions about work. They are free to do the work their own way and respond to their decision. Usually leaders avoid making decisions, do not participate in work units, and are absent when they are needed because leaders give their subordinates complete freedom to push the job to the goals. Sometimes leaders provide subordinates with basic materials and relate the answer and question but avoid the comments. (Niven,2003)

\section{The Effectiveness of Transformational, Transactional and Laissez-Faire Leadership}

Many researches and studies have been done to test the efficiency and the consequences of adopting different Leadership styles on the worker and the corporation itself. For --. For example, a study done in 2008 include of 447 staff working in a care center for the elderly in large Danish local government. The transformational researchers here tested three hypotheses, one of which is the direct relevance between leadership and well-being in followers. The study showed-- that there is a strong relationship between a leader's use of a transformational leadership style in dealing with his employees and their well-being and reducing their level of work stress. (Gumusluoglu et al., 2009). 
Another study by Pearson and Clinton in 2005 concluded that a leader who follows transformational leadership style in dealing with his employees will help them be more creative and motivated, and increase their commitment to the job.

Effective leadership requires promoting others to think innovatively and to continually find out new solutions. Getting people to work at a common goal is not easy. The leader must know when and how to coincide with the thinking of others. People tend to lack skills in problem-solving and ramose thinking, as well as the ability to create innovative solutions to complex problems. Research shows involving people in using their creativity is in the flesh motivating. By encouraging people to think for themselves, the leader creates intrinsic motivation in their followers.

Good leadership promotes transformative and sustainable change. He may be concerned with ethical or regulatory issues. It can define the school's role in the world outside its walls, or it can define the internal dynamics of an organization. Most importantly, it requires good aim vision, if desired - but it also takes persistence (Ekman, 2003, p.2).

Transformational leadership includes the ability to inspire and motivate followers. Research findings support a process-based approach to leadership. This approach assumes that a person is affected by the activation of internal stimuli. An operationbased view of leadership includes the ability to motivate followers to act, while recognizing that the ability to successfully influence others is the essence of leadership (Yukl, 1999). A successful and effective leader has the ability to accept his or her vision, as well as motivate followers to work towards a common goal. (Chemers, 2001). Effective leadership is reinforced when leaders can inspire their followers to embrace change by communicating a compelling vision for the future and stimulating a desire to act in a new way.

House's (1971) Path-Goal Theory sees a successful leader as one who engages followers by aligning their personal goals with the goals of the group. 
Leadership is not just a matter of leaders or leaders and followers. Leadership is the relationship between leaders and subordinates within a social group (Haslam, 2001). Effective leadership is all about providing a vision, creating a social force, and directing that power so that an individual can achieve that vision.

Goal achievement is an issue that leadership studies also address. Within a group, the leader influences or leads in setting the direction or achieving goals. Therefore, leadership involves directing the group towards an endpoint or accomplishing several duties. This trend involves identifying and clarifying the direction according to the external and environmental contingencies of the leader's followers (Zaccaro \& Banks, 2001). Transformational leadership theory includes the thought of inspiring motivation as one way to encourage followers to visualize attractive future situations. (Bass \& Steidlmeier, 1998)

\section{Academic achievement}

Evaluation means a consistent investigation of the value and quality of a particular subject, such as: program, project, personal skills, standards, and needs. Assessment of scholastic achievement is a mechanism of communication that provides information about achieving certain goals (Tyler, 1962). It is a significant matter that deals with human life not only in the lives of young people but also in the lives of teachers and other adults.

Examining a student's achievements means systematically sampling relevant parts of his behavior, so that his level of achievement in relation to academic goals can be assessed (Manor, 1981). Among the factors that take part in the operation of learning and measuring achievements are teachers, students, school material, school, parents and the environment (Nevo, 1991). The student may achieve a high level of achievement provided that the material is presented to him consistently and clearly by the teacher. 
Thus, the teacher plays a substantial role in the teaching work, while measuring achievement serves as a measure for determining the level of his work for the relationship he develops with his students and for measuring the progress of his students in the study material. A teacher who uses evaluation as a tool for the advancement of his students will guide them toward the knowledge presented to them as they participate in the processes of learning and evaluation. This will provide them with a variety of learning options, high level thinking and the possibility of high achievement.

The concept of scholastic achievement includes related concepts such as knowledge, ability, attitudes, skill, success and failure. In addition, scholastic achievements were found to be related to a number of personality variables - selfimage, level of aspirations, socio-economic status, ethnicity, and more.

Providing knowledge is not the sole goal of school learners and can not serve as a single criterion for judging the student's success or effectiveness in school, imparting values, designing approaches and formulating responses to environmental social phenomena are additional educational goals of great value for schoolchildren. It is important to adopt these approaches in order to contribute to a better climate in the classroom and at school, thus causing greater student motivation.

\section{Research Questions}

The study adopted the exploratory research approach to explore the impact of the two school leadership styles (transformational, laissez-faire leadership style) on the school the percentage of outstanding students and on the percentage of dropouts in schools in the Haifa district. 


\section{Participants}

The data will be conducted from the principals and teachers of the Arab high schools in Haifa district. The sample will include 4 schools has rated as "Good" Arab High schools in Haifa district,

The questionnaire was distributed to the Arab high schools in haifa district, that were using leadership style different (transformational, transactional, laissez-faire leadership style) in which consisted of decision makers. The decision makers in this research comprise the research population because they have the power to adopt or not adopt the leadership style. In Arab higher in Haifa district education, the decision makers include the Principal, Deputy Director, and Teachers.

Using a self-administered questionnaire is one of the most frequently used methods for collecting data in research studies (Babbie, 1998). In self- administered questionnaires, the respondents are given the questionnaires and asked to fill them out in their own time and return them by post or email, or let the researcher collect them.

\section{Questionnaire Design}

A considerable amount of attention was paid to the development of the questionnaire, and several drafts including an assessment and pre-test were trialled before choosing the final version of the questionnaire. The questionnaire was designed to obtain information on leadership style used in school. The questionnaire was chosen according to the literature.

Therefore, a set of standards was taken into account during the various steps in the construction of the questionnaire, as recommended by many authors such as Oppenheim (1992) and Collis \& Hussey (2009). 


\section{Result}

\section{Use of Transformational School Leadership Style:}

Schools with a good rate

\section{Arab Schools in Haifa}

It can be noted from the table below that the values of the mean of using transformational school's leadership style to evaluate performance' are 3.87, which is 'High used'. The results show that $19.42 \%$ of the respondents did not use transformational school leadership style at all to evaluate performance; about $13.66 \%$ used them occasionally ('Slightly used') and about 21.6 per cent used them moderately. In addition, about $45.32 \%$ used them 'Significantly' or 'Highly'.

Table Use of Transformational School Leadership Style: Arab schools in Haifa

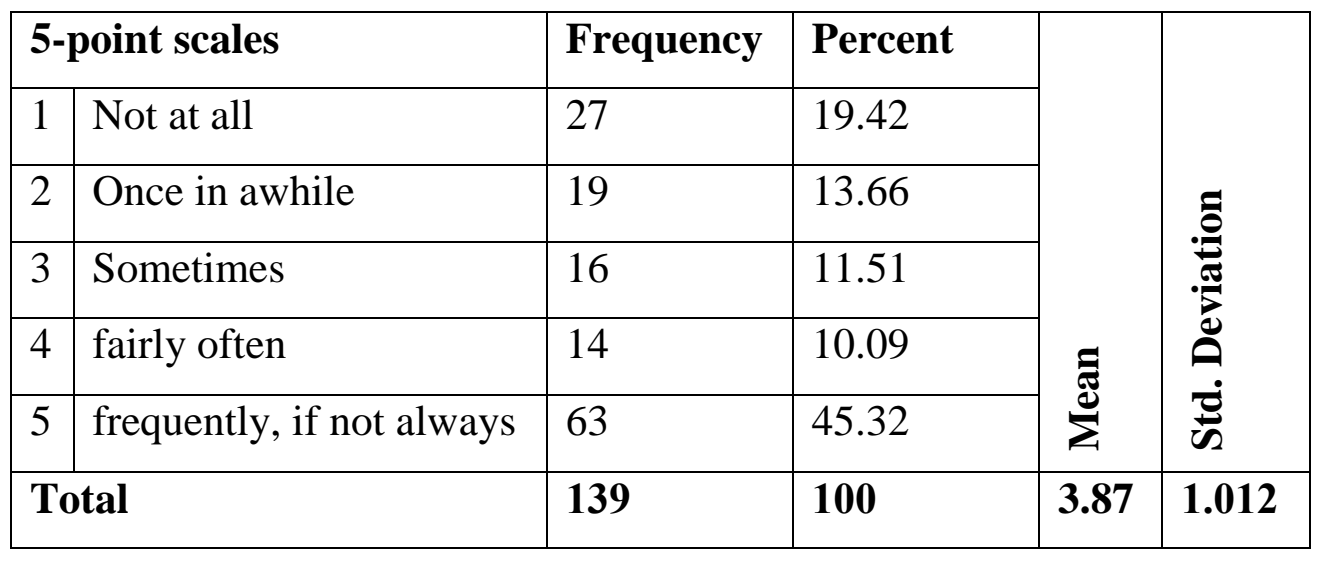

Use of transformational School leadership style: Students with a high school diploma.

Students holding a high school diploma are one of the most important criteria for understanding the extent to which school leadership styles affect the school's culture in the Arab High Schools in Haifa District. 
The results show that about $2.87 \%$ of the respondents to the questionnaire feel that students with a high school diploma is not at all used to evaluate the impact of school leadership patterns on school's culture, about $2.15 \%$ of them feel that they are 'Slightly used' (which is below the 'Moderately used' mark). 5.02\% felt they were moderately used. and about the highest percentage $89.92 \%$ felt they were used more than moderately (Significantly used or highly used). The value of the mean was 4 . (Highly used)

Table Use of transformational School leadership style: Students with a high school diploma

\begin{tabular}{|c|c|c|c|c|c|}
\hline \multicolumn{2}{|c|}{ 5-point scales } & Frequency & Percent & \multirow{6}{*}{ 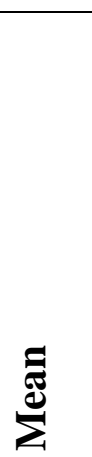 } & \multirow{6}{*}{ 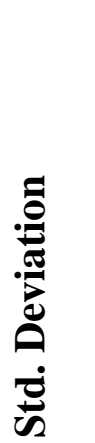 } \\
\hline 1 & Not at all & 4 & 2.87 & & \\
\hline 2 & Once in awhile & 3 & 2.15 & & \\
\hline 3 & Sometimes & 2 & 1.43 & & \\
\hline 4 & fairly often & 5 & 3.59 & & \\
\hline 5 & frequently, if not always & 125 & 89.92 & & \\
\hline \multicolumn{2}{|c|}{ Total } & 139 & 100 & 4.87 & 0.659 \\
\hline
\end{tabular}

Use of transformational School leadership style: Dropout rate

The value of the mean of using transformational school leadership style "Dropout rate" in the Arab High Schools in Haifa District to know the extent to which school leadership styles affect the school's culture is 4.63 negative (Highly used). The results show that about $5.74 \%$ of the respondents answered 'Not used at all' or 'slightly used', about 6.18\% answered 'Moderately used' and about 84.89\% answered 'Significantly used' or 'Highly used'. That is, the dropout rate is $7.4 \%$. 
Academic Journal of Research and Scientific Publishing | Vol 3 | Issue 26

Publication Date: 5-6-2021 ISSN: 2706-6495

Table Use of transformational leadership style: Dropout rate

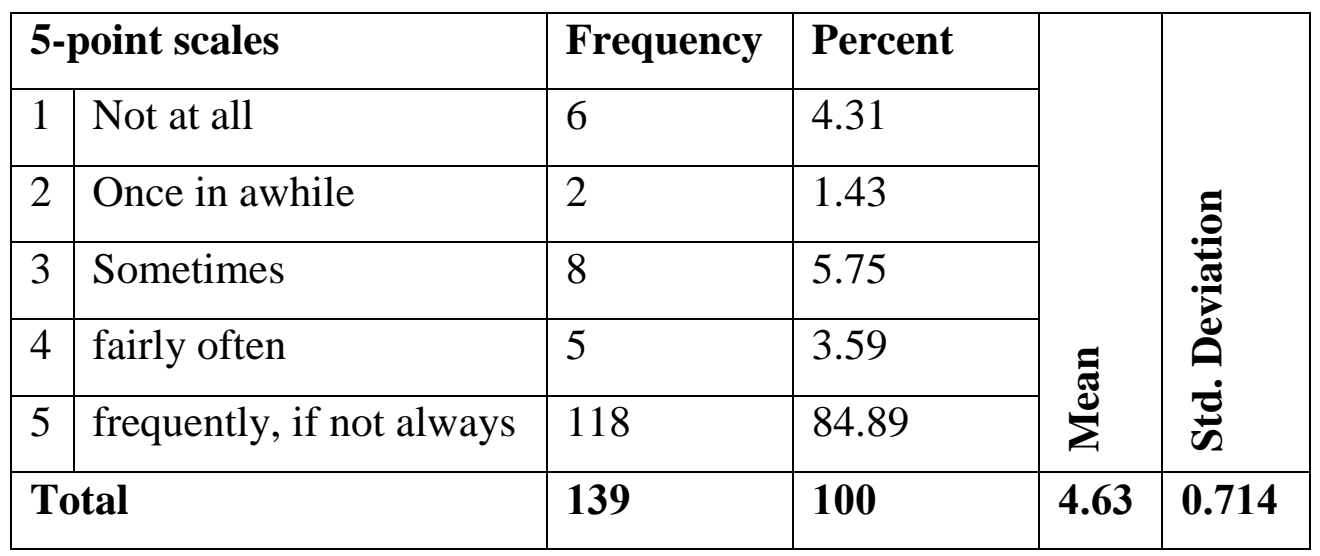

Use of transformational leadership style: The percentage of outstanding students

The importance of other factors affecting school leadership (The percentage of outstanding students) had been measured in this research to find out to what extent the outstanding students are seen as one of the factors affecting school leadership to evaluate on knowing the impact of school leadership patterns on school culture. As shown in the table, the value of the mean 'factors affecting school leadership (outstanding students) to evaluate on knowing the impact of school leadership patterns on school culture is 1.85 , and the results show that about $76.25 \%$ of the respondents answered 'Not used at all' or 'Slightly used'. Also, about $17.98 \%$ said they were moderately used and about 5.75\% said they were more than moderately used ('Significantly used' or 'Highly used').

Table Use of transformational School leadership style: The percentage of outstanding students

\begin{tabular}{|c|c|c|c|c|c|}
\hline \multicolumn{2}{|c|}{ 5-point scales } & Frequency & Percent & \multirow{4}{*}{ 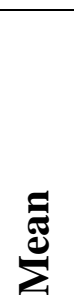 } & \multirow{4}{*}{ 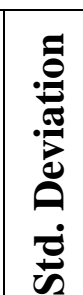 } \\
\hline 1 & Not at all & 78 & 56.11 & & \\
\hline 2 & Once in awhile & 28 & 20.14 & & \\
\hline 3 & Sometimes & 16 & 11.51 & & \\
\hline
\end{tabular}


Academic Journal of Research and Scientific Publishing | Vol 3 | Issue 26

Publication Date: 5-6-2021 ISSN: 2706-6495

\begin{tabular}{|l|l|l|l|l|l|}
\hline 4 & fairly often & 9 & 6.47 & & \\
\cline { 1 - 4 } 5 & frequently, if not always & 8 & 5.75 & & \\
\cline { 1 - 4 } Total & $\mathbf{1 3 9}$ & $\mathbf{1 0 0}$ & $\mathbf{1 . 8 5}$ & $\mathbf{1 . 4 6 8}$ \\
\hline
\end{tabular}

Use of transformational school leadership style: The percentage of students with only 5 units in mathematics

Students with 5 units in mathematics are considered as one of the important factors to evaluate the impact of school leadership patterns on school culture. Results indicate that the high percentage of the students with 5 units in mathematics refers to Successful leadership style, where they reached $37 \%$ and as shown in the table, the values of the average were less than 2 (i.e. less moderately used). The results also show that about $56.11 \%$ of the respondents answered 'Not used at all' or 'slightly used'. About 30.93\% answered 'Moderately used', and about 12.94\% answered 'Significantly used' or 'Highly used'.

Table Use of transformational school leadership style: The percentage of students with 5 units in mathematics

\begin{tabular}{|c|c|c|c|c|c|}
\hline \multicolumn{2}{|c|}{ 5-point scales } & Frequency & Percent & \multirow{6}{*}{$\sum^{\tilde{E}}$} & \multirow{6}{*}{ 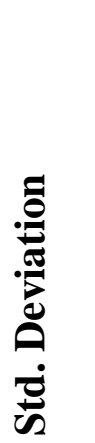 } \\
\hline 1 & Not at all & 31 & 22.30 & & \\
\hline 2 & Once in awhile & 47 & 33.81 & & \\
\hline 3 & Sometimes & 27 & 19.42 & & \\
\hline 4 & fairly often & 16 & 11.51 & & \\
\hline 5 & frequently, if not always & 18 & 12.94 & & \\
\hline \multicolumn{2}{|c|}{ Total } & 139 & 100 & 2.58 & 1.115 \\
\hline
\end{tabular}


Use of transformational school leadership style: The percentage of students with 5 units in English

Students with 5 units in English are considered as one of the important factors to evaluate the impact of school leadership patterns on school culture as the percentage reached $63.6 \%$ and as shown in the table, the values of the average were more than 3 (i.e. more moderately used). The results also show that about $20.8 \%$ of the respondents answered 'Not used at all' or 'slightly used', about $48.19 \%$ answered 'Moderately used', and about 30.93\% answered 'Significantly used' or 'Highly used', which is above 'Moderately used.

Table Use of transformational school leadership style: The percentage of students with 5 units in English

\begin{tabular}{|c|c|c|c|c|c|}
\hline \multicolumn{2}{|c|}{ 5-point scales } & Frequency & Percent & \multirow[b]{6}{*}{$\sum_{\Sigma}^{\tilde{E}}$} & \multirow{6}{*}{ 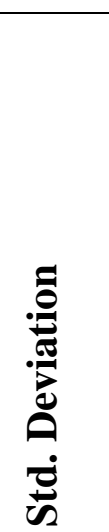 } \\
\hline 1 & Not at all & 17 & 12.2 & & \\
\hline 2 & Once in awhile & 12 & 8.6 & & \\
\hline 3 & Sometimes & 29 & 20.86 & & \\
\hline 4 & fairly often & 38 & 27.33 & & \\
\hline 5 & frequently, if not always & 43 & 30.93 & & \\
\hline \multicolumn{2}{|c|}{ Total } & 139 & 100 & 3.56 & 1.118 \\
\hline
\end{tabular}

\section{Summary of the use of transformational school leadership style to know the} Influence of the School Leadership Styles on the School Culture

The use of transformational school leadership style in the Arab High Schools in Haifa District is presented in the table. It can be noted from the table that the highest value for using transformational school leadership style on "Dropout rate" was 4.3 and above 4 (i.e. above highly used). 
The second rank was for students with a high school diploma, and the third was for using the percentage of outstanding. The fourth was for the percentage of those with 5 units in English, and the last rank was for the percentage of those with 5 units in mathematics.

Table Summary of the use of transformational school leadership style to know the Influence of the School Leadership Styles on the School Culture

\begin{tabular}{|l|l|l|l|}
\hline $\mathbf{N}$ & Use of standard transformational leadership style & Mean & Rank \\
\hline $\mathbf{1}$ & $\begin{array}{l}\text { Use of school leadership style transformational: Students } \\
\text { with a high school diploma. }\end{array}$ & $\mathbf{4 . 8 7}$ & $\mathbf{1}$ \\
\hline $\mathbf{2}$ & $\begin{array}{l}\text { Use of school leadership style transformational: Dropout } \\
\text { rate }\end{array}$ & $\mathbf{4 . 6 3}$ & $\mathbf{2}$ \\
\hline $\mathbf{3}$ & $\begin{array}{l}\text { Use of school leadership style transformational: The } \\
\text { percentage of outstanding }\end{array}$ & $\mathbf{1 . 8 5}$ & $\mathbf{5}$ \\
\hline $\mathbf{4}$ & $\begin{array}{l}\text { Use of school leadership style transformational: The } \\
\text { percentage of those with 5 units in mathematics }\end{array}$ & $\mathbf{2 . 5 8}$ & $\mathbf{4}$ \\
\hline $\mathbf{5}$ & $\begin{array}{l}\text { Use of school leadership style transformational: The } \\
\text { percentage of those with 5 units in English }\end{array}$ & $\mathbf{3 . 5 6}$ & $\mathbf{3}$ \\
\hline
\end{tabular}

Non-use of laissez-faire leadership style in school: Schools with a good rate.

The values of the mean of 'Non-use of laissez-faire leadership style to evaluate performance' are 3.21, which is 'Highly used'. The results show that $41.92 \%$ of the respondents had not used laissez-faire leadership style in school at all to evaluate performance; about 15.82 per cent had used it moderately. And, about $25.17 \%$ used it 'Significantly' or 'Highly'. 
Academic Journal of Research and Scientific Publishing | Vol 3 | Issue 26

Publication Date: 5-6-2021 ISSN: 2706-6495

Non-use of laissez-faire leadership style in school: School in Al-Muthalath Al-

Shamali.

\begin{tabular}{|c|c|c|c|c|c|}
\hline \multicolumn{2}{|r|}{ 5-point scales } & \multirow{2}{*}{$\begin{array}{c}\text { Frequency } \\
35\end{array}$} & \multirow{2}{*}{$\begin{array}{c}\text { Percent } \\
25.17\end{array}$} & \multirow{6}{*}{ 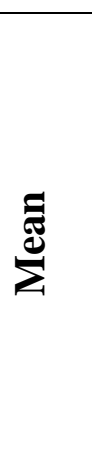 } & \multirow{6}{*}{ 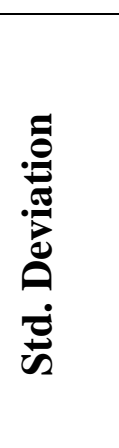 } \\
\hline 1 & Not at all & & & & \\
\hline 2 & Once in awhile & 24 & 17.29 & & \\
\hline 3 & Sometimes & 14 & 10.07 & & \\
\hline 4 & fairly often & 8 & 5.75 & & \\
\hline 5 & frequently, if not always & 58 & 41.72 & & \\
\hline \multicolumn{2}{|c|}{ Total } & 139 & 100 & 3.21 & 1.130 \\
\hline
\end{tabular}

Non-use of laissez-faire leadership style in school: Students with a high school diploma

The table shows the effect of the non-use of laissez-faire leadership style in school, where the average of students completing high school reached 4.82. The percentage of teachers who used this method was $2.15 \%$, while the moderate use of it amounted to $5.02 \%$, while the highest rate of non-users was $92.08 \%$.

Non-use of laissez-faire leadership style in school: Students with a high school diploma

\begin{tabular}{|c|c|c|c|c|c|}
\hline \multicolumn{2}{|r|}{ 5-point scales } & Frequency & Percent & \multirow{6}{*}{ 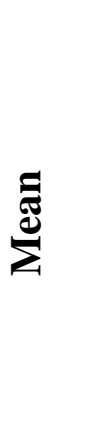 } & \multirow{6}{*}{ 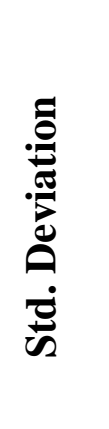 } \\
\hline 1 & Not at all & 3 & 2.15 & & \\
\hline 2 & Once in awhile & 1 & 0.71 & & \\
\hline 3 & Sometimes & 3 & 2.15 & & \\
\hline 4 & fairly often & 4 & 2.87 & & \\
\hline 5 & frequently, if not always & 128 & 92.08 & & \\
\hline & al & 139 & 100 & 4.82 & 0.678 \\
\hline
\end{tabular}


Non-use of laissez-faire leadership style in school: Dropout rate

The value of the mean of 'Non-use of laissez -faire leadership style Dropout rate in the Arab High Schools in Haifa District to know how leadership styles affect the school's culture is 4.9 negative. The results show that this style was not used; the moderate use of it amounted to $5.02 \%$, while the highest rate was $92.08 \%$.

Non-use of laissez-faire leadership style in school: Dropout rate

\begin{tabular}{|c|c|c|c|c|c|}
\hline \multicolumn{2}{|r|}{ 5-point scales } & \multirow{2}{*}{$\begin{array}{c}\text { Frequency } \\
0\end{array}$} & \multirow{2}{*}{$\begin{array}{c}\text { Percent } \\
0\end{array}$} & \multirow{6}{*}{ 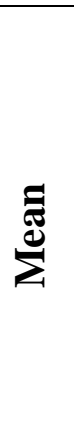 } & \multirow{6}{*}{ 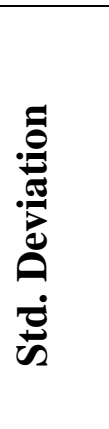 } \\
\hline 1 & Not at all & & & & \\
\hline 2 & Once in awhile & 1 & 0.71 & & \\
\hline 3 & Sometimes & 3 & 2.15 & & \\
\hline 4 & fairly often & 4 & 2.87 & & \\
\hline 5 & frequently, if not always & 131 & 94.24 & & \\
\hline \multicolumn{2}{|c|}{ Total } & 139 & 100 & 4.9 & 0.659 \\
\hline
\end{tabular}

Non-use of laissez-faire leadership style in school: The percentage of outstanding students

The percentage of outstanding students had been measured in this research to find out the influence of the school leadership style on the percentage of outstanding students, to evaluate the impact of school leadership patterns on school culture. As shown in table, the value of the mean 1.87 , and the results show that about $43.16 \%$ from the teachers used the style, 2.87 did not use it permanently. The ratio was $19.41 \%$. 
Academic Journal of Research and Scientific Publishing | Vol 3 | Issue 26

Publication Date: 5-6-2021 ISSN: 2706-6495

Non-use of laissez-faire leadership style in school: The percentage of outstanding students

\begin{tabular}{|c|c|c|c|c|c|}
\hline \multicolumn{2}{|r|}{ 5-point scales } & \multirow{2}{*}{$\begin{array}{c}\text { Frequency } \\
60\end{array}$} & \multirow{2}{*}{$\begin{array}{c}\text { Percent } \\
43.16\end{array}$} & \multirow{6}{*}{ 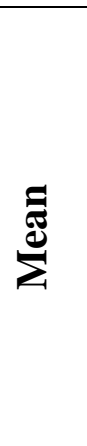 } & \multirow{6}{*}{ 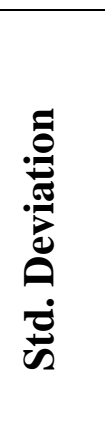 } \\
\hline 1 & Not at all & & & & \\
\hline 2 & Once in awhile & 48 & 34.53 & & \\
\hline 3 & Sometimes & 24 & 17.26 & & \\
\hline 4 & fairly often & 3 & 2.15 & & \\
\hline 5 & frequently, if not always & 4 & 2.87 & & \\
\hline \multicolumn{2}{|c|}{ Total } & 139 & 100 & 1.87 & 1.456 \\
\hline
\end{tabular}

Non-use of laissez-faire leadership style in school: The percentage of students with 5 units in mathematics

Non-use of laissez-faire leadership style in school has a good effect on students obtaining 5 units in mathematics, as the percentage of them is $37 \%$. And as shown in table, the values of the average were less than 2 . The results also show that about $5.75 \%$ of the respondents answered 'Not used at all' or 'slightly used', about $17.98 \%$ answered 'Moderately used', and about 56.11\% answered 'Significantly used' or 'Highly used'.

\section{Findings and Discussion}

The results showed that the use of the transformational leadership style by teachers and administrators had a significant impact on the decrease of the student dropout rate of 4.63 negative, and the use of this style had the greatest impact on students obtaining a diploma in high school, which shows the positive effect of the leadership style Transformational school culture. 
The results of the study are fixed with a study by Jantzi and Leithwood (1996): The significant attachment between transformational leadership and school culture results confirm the study by Jantzi and Leithwood (1996) who studied transformational school leaders are in constant pursuit of three primary goals. They are assisting staff in developing and maintaining a collaborative and professional school culture, fostering the development of staff skills and knowledge, and helping staff solve problems together effectively. Considering the overall considerable values shown in the findings, it can be concluded that the transformational leadership behavior had a significant effect on the school culture.

This impact was clearly perceived on high school teachers, who were aware of the qualities of principal leadership and its effect on the existing school culture. Especially on student commitment and high success rates.

The results showed that the Non-use of the transformational leadership style by teachers and administrators had a significant impact on the increase of the student dropout rate of 3.9 positive, and the use of this style had the greatest impact on students not obtaining a diploma in high school, which shows the negative effect of the leadership style nonuse Transformational school culture. Low percentage of students obtaining math and English language units.

The results showed that the Non-use of laissez-faire leadership style by teachers and administrators had a significant impact on the decrease of the student dropout rate of 4.9 negative, and the use of this style had the greatest impact on students obtaining a diploma in high school, which shows the Positive effect of not using leadership style "Non-use of laissez-faire" on school culture.

Leadership characteristics of the principal and teachers affect school culture. The results of this study show statistical significance of transactional and transformational, and laissez-faire leadership, with school culture. Higher levels of both transactional and transformational leadership were associated with higher levels of school culture. 
This study's findings were consistent with Schein (1992), Bulach (2001), Sergiovanni and Corbally (1984), and McCall (1994) who found that principal leadership had considerable effects on school goals, school culture, policies, and organization. In this study, the use of transactional leadership resulted in a positive school culture as rated by teachers.

Transactional leadership and transformational are central in maintaining an organization. The transactional leadership traits are important to the organization. A principal's leadership style enhances, encourages and nurtures a positive school culture. Transactional leadership is Flexibility and Discretion, and occurs when leaders intervene to make some correction and generally involves corrective criticism.

Analyzing investigated the use of School Leadership Styles (transformational, transactional, laissez-faire). Stated that leadership characteristics and school culture affect student achievement. This study found statistical significance among the relationship between transactional leadership and student success.

The values of the mean of using transformational schools leadership style to evaluate performance' are 3.47, which is 'Highly used'. The results show that $8.63 \%$ of the respondents had not use transformational school leadership style at all to evaluate performance; about 5.75\% used them occasionally ('Slightly used') and about 33.09 per cent used them moderately. In addition, about $52.51 \%$ used them 'Significantly' or 'Highly'. This means that using the transformational leadership style largely by principals and teachers at a rate of $52.51 \%$ led to achieving a high success rate for high school students with a high rate of $86.75 \%$ in various units (mathematics, English).

It also reached the percentage of outstanding Students resulting from using of transformational school leadership style, Medium the value of the mean 2.15. While Non-use of transformational school leadership style, the percentage of outstanding students the value of the mean is 4.84 negative. 
To a study Consistent with Fuller (1989), transformational leadership was found to be significant to learning community and teacher efficacy, particularly in student success and outstanding.

The findings of this study differed markedly from Hellinger, Beckman, and Davis (1996), who f ound that there was no direct effect of leadership styles on student achievement. In this study transactional leadership was found to have a significant link to student achievement. McMillian (1996) suggested the relationship between a principal's leadership style and levels of student achievement is extremely complex.

The results show the impact of using laissez-faire leadership style in school on the percentage of students completing the secondary stage. The average of students completing high school reached 3.33 negative. And the ratio of students completing high school reached 1.67. This indicates the negative impact of using this method by principals and teachers on students' completion of high school.

\section{References}

1. Avolio, B.J. (2005). L Yukl, G., \& Falbe, C. M. (1990). Influence tactics and objectives in upward, downward, and lateral influence attempts. Journal of Applied Psychology, 75(2), 132-140

2. Bass, Bernard M., Bass \& Stogdill's Handbook of Leadership: Theory, Research, and Managerial Applications. New York: Free Press, 1990.

3. Collis, Jill, \& Hussey, Roger. (2009). Business research: a practical guide for undergraduate $\&$ postgraduate students. Basingstoke: Palgrave Macmillan.

4. Graham, M.W. \& Messner, PE. (1998). Principals and job satisfaction international tional Journal of Educational Management, 12(5), 196-202

5. Hoy, W. K., \& Tartar, C. J. (2010). Swift and smart decision making: Heuristics that work. International Jog " nal of Educational Management, 24 (4), 351 - 358 
6. McClelland D. (1961). The achieving society. New York: The Free press.

7. Oplatka, Y. (2003). School change and self-renewal: some reflections from life sto- ries of women principals. Journal of Educational Change, 4(1), 25-43

8. Oplatka, Y. (2005). Imposed school change and women teachers' self-renewal: A new insight on successful implementation of changes in schools. School Leader- ship and Management, 25(2), 171-190.

9. Oplatka, Y. (2006). Going beyond role expectations: Towards an understanding of the determinants and components of teacher organizational citizenship behav- ior. Educational Administration Quarterly, 42(3), 385-423.

10. Oplatka, Y. (2007). Managing emotions in teaching: Towards an understanding of emotlon displays and caring as non-prescribed role elements. Teacher College Record, 109(6), 1374-1400.

11. Robert E., \& Rohrbaugh, John. (1983). A Spatial Model of Effectiveness Criteria: Towards a Competing Values Approach to Organizational Analysis. Management Science, 29(3), 363-377. doi: 10.1287/mnsc.29.3.363

12. Sergiovanni, TJ \& Carver, ED. (1980). The new school executive. New York

13. Simchi, L. (2004). Self-image and burnout of teachers, youth promotion workers and coordinators. Connection for the purpose of obtaining a Master's degree. Ramat-Gan: BarIlan University

14. Yukl, G., \& Falbe, C. M. (1990). Influence tactics and objectives in upward, downward, and lateral influence attempts. Journal of Applied Psychology, 75(2), 132-140.

15. Liljestrom, A., Roulston, K., \& Demarrais, K. (2007). There is no place for feeling like this in the workplace: Women teachers' anger in school settings. In PA. Schutz \& R. Pekrun (eds). Emotion in education (pp. 275-291). San Diego Elsevier

16. . NMSA (2008), (National Middle School Association), 2008. NMSA Research Summary: Courageous, Collaborative Leadership (February), Retrieved 12.6.08

17. Zembylas, M., Charalambous, C., Charalambous, P, \& Kendeoub, P. (2011). Promoting peaceful coexistence in conflict-ridden Cyprus: Teachers' difficulties and 
Academic Journal of Research and Scientific Publishing | Vol 3 | Issue 26

Publication Date: 5-6-2021 ISSN: 2706-6495

emotions towards a new policy initiative. Teaching and Teacher Education, 27, 332-341.

18. Williams, M. \& Burden, R.L. (1997). Psychology for Language Teachers: A Social Constructivist Approach. Cambridge: Cambridge University Press.

19. Richard T Mowday, Richard M Steers, Lyman W Porter,The measurement of organizational commitment,Journal of Vocational Behavior,Volume 14, Issue 2,1979, Pages 224-247.

Copyright (C 2021 Kawther Younes, Yousef Daher, AJRSP. This is an open-access article distributed under the terms of the Creative Commons Attribution License (CC BY NC).

Doi: $\underline{\text { doi.org/10.52132/Ajrsp.e.2021.262 }}$ 